\title{
Availability of and accessibility to maternal healthcare services in the northern Bangladesh
}

\section{Bijoy Krishna Banik}

Department of Sociology, the University of Rajshahi, Rajshahi, Bangladesh

Email address:

bkbanik2001@yahoo.com

To cite this article:

Bijoy Krishna Banik. Availability of and Accessibility to Maternal Healthcare Services in the Northern Bangladesh. American Journal of Health Research. Vol. 3, No. 2, 2015, pp. 63-75. doi: 10.11648/j.ajhr.20150302.13

\begin{abstract}
Poor women, in both rural and urban areas in the northern region of Bangladesh, suffer from high maternal mortality rates, and compared to other regions, this group also has a low proportion of up-taking ante natal care (ANC) and of births assisted by skilled attendants. This endeavour therefore took an attempt to critically examine the availability of and accessibility to maternal health care (MHC) services, provided by government and non-government organisations (NGOs) in the northern part of Bangladesh, with the specific objective of finding out how far poor women had the availability of and accessibility to MHC services. The study used both primary and secondary data to meet its objectives. Triangulation of methods (questionnaire interviews of service users and providers, and observations) were employed to collect primary data. A large number (160) of mothers who were pregnant or delivered at least one baby during the last ten years and the heads of relevant health centres were interviewed. An assortment of articles, reports, theses and books were consulted in complementing and substantiating the arguments in this study. The main findings of the study suggest that there has been an increase in the availability of and accessibility to MHC services. However, the increment varies across regions and social groups. Lastly, it concludes that rural, poor and less educated mothers have less availability of and access to MHC services compared to urban, non-poor and better educated women.
\end{abstract}

Keywords: Availability, Accessibility, Maternal Healthcare Services, Poor Women, Rajshahi, Bangladesh

\section{Introduction}

The Government of Bangladesh has been undertaking a number of five-year plans since the independence of 1971. The concept of 'health' found in all national plans before 2000 when the National Health Policy was introduced (Osman, 2004: 76-77). The First Population Policy—one of the earliest and most successful policies-was adopted in 1976 under which the national family planning program was adopted. The notion of the 'Primary Health Care (PHC)' was first independently introduced in the Second Five-Year Plan (1981-85) following the announcement of Alma Ata Conference of 1978 which boldly proclaimed "Health for All by the Year 2000". The Third Five Year Plan (1985-90) continued to focus on the provision of PHC services (Banik, 2003: 257) and also added one new dimension in health services which focused on Maternal and Child Health (Osman, 2008: 265).

Bangladesh executed many collaborative projects and programs with the World Bank and other donor consortiums during the Fourth Five Year Plan (1990/91-94/95). Meanwhile, the Health Sector Reform, thereby the integration of the development partner vis-a-vis NGOs in service provisioning, shifting its strategy from the project to program-driven approach, and decentralising delivery systems, was undertaken in 1996/97. The main objective of the reform policy was to cater the Package of Essential Service (ESP), resultantly slowing down high population growth (GoB, 1998; Islam and Tahir, 2002: 157; Pearson, 1999:3). Now there has been growing a trend among both GOs and NGOs to provide health care services collaboratively in urban areas, particularly metropolitan cities, and rural areas with a limited extent.

Bangladesh is a developing country where people largely depend on the state for healthcare services and where health care service delivery system is largely based on the PHC concept. This system mainly targets to provide health care services at the rural countryside, thereby providing different 
types of healthcare services at five levels: Home and Community level; Union level: Union Health Sub-Centre (UHSC) /Union health and Family Welfare Centre (UHFWC); Upazila level: Upazila Health Complex (UHC); District level: District Hospital; and National level. Each district hospital serves a population of roughly 2.5 million whereas the UHC provides services to a population of about 0.2 million (Hossain and Ross 2006: 321). It could be said that, like many third world countries (kleinman, 1980; Coppo et al 1992), medical pluralism or the existence of different therapeutic systems in a homogeneous socioeconomic setting is an important aspect of health care system in Bangladesh (Ahmed et al 2000: 362, 2003: 308; Desmet et al 1999: 99-100). They range from self-care to folk and western medicine.

As claimed in a plethora of studies (Ahmad, 2003; Ahmed, 2002; Ahmed \& Islam, 2012; Anwar et al 2009; Barkat et al 1997; Daily Star, March 1, 2012; Dewan, n.d; Hossain et al 2003; Hossain et al 2005; Islam et al 2005; McPake \& Koblinsky, 2009; MOHFW, 2000; MOHFW, 2010; Mridha et al 2009; Osmani, 2010; Rahman, 2007 ), all these efforts (giving more emphasis on PHC concept, increasing involvement of NGOs in service provision along with the government sector, bringing reform in the health sector thereby decentralizing service delivery pattern) have resulted in bringing about revolutionary change in health sector. Increasing the availability of and accessibility to PHC services is one of the prime factors for this change. As the situation of Rajshahi region, one of the largest regions, is worse in many health respects (detailed in methodology section), exploring the availability of and accessibility to primary, maternal in particular, healthcare services for the Rajshahi division is a time requirement.

The main focus of this effort was thus to find out the availability of various primary, particularly maternal, healthcare options in the study area and the extent to which they had access to these services. The rest of the paper is organized in this manner. The next part gives ideas about the ways the study was conducted which is followed by highlighting main results of the study. The final part draws a conclusion.

\section{Methodology}

The study basically used both primary and secondary sources of data. Mixed methods were used for collecting primary data. They include interviews of service recipients through interview schedule, interviews of service providers through checklist and observation. The main reasons for choosing mixed methods were to understand and interpret the problems, to explore the availability of and accessibility to health care services, and to mitigate problems of validity and bias (Marshall and McKeon, 1996: 151; Germov, 2002: 12).

The study was conducted by using multi-stage sampling technique which included purposive for site selection, systematic random sampling for household selection and finally snowball sampling for respondent selection.

\subsection{Area Selection}

The main focus of the study was to highlight the availability of and accessibility to MHC services. In this regard, out of seven divisional regions in Bangladesh, Rajshahi region was selected due to its worst condition. The following figures suggest that Rajshahi situation is not better compared to other regions in Bangladesh.

- Maternal health situation in Rajshahi division is worse than other divisions in Bangladesh. The maternal mortality rate in Rajshahi and Bogra regions within Rajshahi division is 2.9 and 3.0 respectively while the figure for Barisal, Pabna, Tangail and Dinajpur is 2.6, 2.6, 2.6 and 2.8 interchangeably (BIDS, 2003).

- The proportion of delivery done by qualified doctors in Rajshahi is 22.1 percent which is lowest compared with other divisions (NIPORT et al 2012).

- $\quad$ The percentage of delivery held in a facility centre in Rajshahi is 13.2 whereas that in Khulna and Dhaka is 22.4 and 16.9 respectively (NIPORT et al 2009).

- The percentage of mothers with at least one ANC visit in Rajshahi is 71.3 while the figure for Khulana and Rangpur is 77 each (NIPORT et al 2012).

- $\quad$ Around 60 percent of mothers in Rajshahi division had no access to ANC provided by medical personnel whereas only half of the mothers in Khulna division had no access (NIPORT, 2001).

\subsection{Site Selection}

The study selected three different areas of Rajshahi division (Bogra city, Rajshahi city and Shapahar) based on the scale of rural-urban continuum, remoteness and clustering poor households. Rajshahi and Bogra are metropolitan cities where government and private organisations, including NGOs, provide basic healthcare services. Shapahar, where government-provided healthcare services are available, is in the rural area of Rajshahi division close to the border with India and far away from the heart of Rajshahi and Bogra cities.

For Bogra and Rajshahi city, a search was made on the number of wards. In Bogra, from a total of 20 wards, Ward no. 6 , where poor families usually lived, was selected. From within this ward, one particular area, namely North Chelopara, was chosen. Similarly, two very remote wards (no $17 \& 30$ ) of a total of 30 ones, in Rajshahi, were selected. Kazla (Ward no 30) is situated in the eastern corner of the city and about eight kilometres away from the central business district. Naodapara (Ward no 17) is located in the northern part of the city and around 15 kilometres away from the city centre. From Shapahar upazila, one village located far away from the administrative headquarter was selected for administering interviews of the women. This villageNirmoil, had poor communication facilities and limited forms of transportation for travel.

\subsection{Development of Research Instruments}

With some addition and correction of an initially developed draft interview schedule, a semi-structured 
interview schedule (including both open and close ended questions) was finalized for pre-testing. One-day long intensive training was given to the research assistants (RAs) with objectives of giving them orientation about the issues to be studied and how interview schedule should be filled up. Getting feedbacks from the pre-testing, necessary correction and modifications were made in the interview schedule. It was then ready for conducting interviews among the recipients of MHC services.

Once the interview schedule was finalised after the pretesting, RAs prepared themselves for conducting interviews. Field investigation began in early October and ended in late December 2010. Each interview took 30 to 45 minutes on an average. Sixty mothers were interviewed in Bogra and Rajshahi each and 40 in Shapahar, therefore the total number of respondents is 160 . One street from the selected areas was chosen randomly. Then the first woman either being pregnant or delivering at least one baby in the last ten years was randomly picked up for interview. Based on her knowledge regarding the availability of nearby mothers/women with pregnancies/babies, the consecutive respondents were selected (by using snowball sampling technique). It should be mentioned here that RAs were instructed that they should interview mothers from different clusters and avoid the next door neighbour of the interviewee. The basic principle for giving this instruction is to collect information from heterogeneous respondents, albeit they are homogenous in basic socio-economic parameters, thereby maintaining quality of the study. Once the interviews of females were over, we checked where the respondents invariably went for MHC services. Heads of these healthcare centres were targeted to interview. The total number of interviews conducted is seven - three each in Shapahar and Rajshahi and one in Bogra.

After completing the field investigation, all the interview schedules were edited and some errors were detected and corrected accordingly. All data was coded and analyzed through the Statistical Package for Social Sciences (SPSS) program. Then it was presented in a tabular form. Besides these, the study used different reports, articles and news paper features for making arguments stronger.

\subsection{Profiles of the Respondent}

Most respondents (see Table 1 in appendix) were below 35 years of age $(94.3 \%)$ and married $(96.8 \%)$. Around 90 percent of respondents were married below the age of 20 . Marriage at an early age is still prevalent and it could be one of the main reasons that caused early-married mothers to be at high risk, including death. More than three-fifth mothers were 25 years old or below. That means they attained motherhood immediately after marriage. It could be that they had more than one baby within five to seven years of their marital life, as they are culturally and socially conditioned to have babies one after another. Although the study targeted to interview pregnant women or mothers with at least one baby in the last ten years, the majority of mothers delivered at least one baby in the last five years. So there was little scope for recall bias. Sixty three out of 160 respondents were illiterate, while 44 and 50 had primary and secondary levels of education respectively. Around 78 percent of respondents had three-member- oriented families, while 19 percent had four to six member-based families.

As revealed in Table 2 (in appendix), around 62 percent of respondents were Muslims and 34 percent Hindus. Almost all respondents were housewives. Around 44 percent of respondents reported that their monthly family income was less than 5,000 Taka (US\$ 1=about 80 Taka), while half of the respondents reported an income between 5001 and 10,000 Taka. Only six percent of families had more than 10,000 Taka monthly incomes. Less than three quarters of respondents (71.2\%) lived in kutcha type of residences, followed by semipucca (18.1\%), tin shed (5.7\%) and pucca (5\%). More than half the respondents had bed, box and clothes hanger. The percentage of respondents having no household furniture was 18. Interestingly, the number of respondents having a television was quite high compared to a more useful item, such as the refrigerator or a fan. It is important to note here that 37 percent of respondents reported that they did not have any consumer goods. Among respondents with consumer goods, the majority (43\%) had only a single one, while 15 percent had two consumer goods. Only one-fifth of respondents had either two or more than two consumer goods.

If we take US\$2 as a measure of income poverty, around 44 percent respondents were below the poverty line (Table 2 in appendix). If poverty is multi-dimensionally treated, around 70 percent respondents were deprived of education and a decent living standard. It is worthy to mention here that no electricity was available in the study rural area where only rich people had solar energy. According to Alkire and Santos (2010), one household can be assessed as deprived if no household member has completed five years of schooling; household has no access to electricity; it has dirt, sand or dung floor; and it does not own more than one item of consumer goods. Based on the criteria set by them, $66.8 \%$, $71.2 \%$ and $80 \%$ households in the studied areas were deprived from education, decent housing and not having more than one consumer item respectively.

\section{Main Findings and Discussions}

\subsection{Availability of Healthcare Services}

Bangladesh has made considerable improvement in coverage of healthcare services since independence. The number of government hospitals increased from 131 in 1975 to 660 in 1999 and then to 678 in 2005-06. Similarly, the number of private hospitals, clinics and nursing homes together rose from 613 in 1999 to 2,501 in 2010. The figures indicate that the private sector has been expanding more quickly than the public since the last decade. The figures for hospital beds also support the above argument. Between 1999 and 2010, the number of hospital beds in both the public and private sectors went up to 39,341 and 42,237 from 31,772 and 11,371 respectively. This incremental rise 
resulted in enhancing people's availability of hospital beds. Thus, at present, one bed is available for 1,860 people, whereas, in 1999, the number was 3,083 (MOHFW, 2000; MOHFW, 2010; Osmani, 2010).

The MHC facilities are also increasing to meet the growing demand for obstetric care owing to the raising of awareness about seeking healthcare during pregnancy through mass education, increasing women's movements and participations in different activities, although this increment is not up to the standard requirements the WHO set in 2005. The government has divided the emergency obstetric care (EmOC) into three tiers i.e., first aid ${ }^{1}$, basic ${ }^{2}$, and comprehensive $^{3}$. First aid is provided at the union level, basic at upazila, basic and comprehensive at the district, and comprehensive at the divisional level (Barkat et al 1997). Almost all government hospitals at district and above levels have EmOC. Out of 4,451 unions and 490 upazilas, 3,632 and 402 respectively have EmOC (Table 1). Presently one basic emergency obstetric care (BEmOC) facility serves 0.66 million people, while the figure for comprehensive emergency obstetric care (CEmOC) is 0.64 million (Dewan, n.d). A study dispels the above claim reporting that around one-fourth BEmOC and one-fifth CEmOC of WHOrecommended facilities are available (Mridha et al 2009). One of the possible reasons for this dearth is that every centre at each level might need more than one BEmOC or CEmOC facility because WHO recommends each facility for a certain number of people. Another study claimed that the number of CEmOC facilities increased from 2 to 32, whereas that for BEmOC (20) remained the same in Khulna division (one of the seven divisions) between 2000 and 2002. That means, the availability of CEmOC significantly increased: 0.2 facility centre was available for 500,000 population in 2000 , whereas that proportion turned into 1.0 in 2002 (Islam et al 2005). However, this development is yet to meet the WHO standard of one CEmOCs per 500,000. Certainly, MHC services are in need of improvements. Current data hints that, in 2009, only four out of 9.4 million mothers received some form of MHC services (Daily Star, March 1, 2012).

PHC services in rural areas are meagre in comparison to urban areas. Public and private (including the NGO sector) are providing $\mathrm{PHC}$ services in urban areas, whereas only government and some NGOs are involved in limited forms of healthcare services in rural areas. Even in many cities, more essential healthcare services are available in private than in public hospitals (koehlmoos et al 2011). As qualified health personnel prefer staying in town areas, private sectors can easily recruit them for rendering their services to patients in urban localities. NGOs are keener to serve urban areas as it is easy to target service users, to demarcate catchment areas and

1 It includes administering parenteral Oxytocin drug (Ergometrine), parenteral antibiotics and parenteral sedatives/anticonvulsants.

2 It performs all functions of first aid and the manual removal of placentas and assisted vaginal delivery (vacuum extraction, forceps).

3 It includes all functions of first aid and basic as well as surgery and blood transfusion. to provide services at the micro level. By doing these, they can easily bring positive results in catchment areas which reflect the success of NGO activities.

Three reasons for the availability of the NGO-run healthcare services in urban areas are identifiable from the interviews of health personnel. These are: easy identification and targeting disadvantaged people, who reside at certain points of cities, for rendering services; achieving the target is not complicated, as the coverage is limited and easy for people to access physically with the support of good communication systems; and health personnel tend to live in urban areas where other facilities, such as career advancement and educational facilities, for all family members are available. The study (Table 2) found a rural-urban differential in the availability of PHC centres.

As reported in Table 2, in Bogra, most respondents visited either Shishu Mongol (27 times) or urban centre (24 times) for MHC services. Mothers were not keen on visiting the government tertiary hospitals despite many of these being in their localities. In Rajshahi, a vast majority of respondents visited the urban centres, while, in Shapahar, respondents almost chose the government healthcare centres. Urban people have better options as a larger number of NGOs-operated healthcare centres are available to them. Overall, government healthcare centres do not seem to be popular for those who have other options (NGO or private centres) for healthcare services. It is also important to mention here that 40 percent of respondents living in the rural areas did not receive MHC services from any health centres.

This study (Table 3) also found variance in the availability of nearest health centres in different areas. Most respondents in both Bogra and Rajshahi reported urban centres as closest to where they live, whilst almost all respondents in Shapahar said that the UHSC was the nearest.

In other words, the UPHCP has been able to reach the doorsteps of the people with healthcare services in both Bogra and Rajshahi slums, whereas Shapahar did not provide that option apart from the government UHSC. This indicates that NGOs penetration in service delivery was higher in urban than rural areas.

Rural areas are inadequately served by these though the Health Wing took steps for upgrading rural health centres vis-a-vis UHCs and, as of 2007, only one-fifth of them were upgraded (Mridha et al 2009: 136). Based on statistical data, Chowdhury (2004 in Rahman et al 2005: 4) argues that most of the specialised hospitals and their services are available in urban areas where around 30 percent of people reside. His figures indicate that 44 and 28 percent of the government and private facilities in that order are available for the rural areas, whereas 56 percent government and 72 percent private healthcare facilities are urban-based. 
Table 1. Government facilities for EmOC services, 2006.

\begin{tabular}{llll}
\hline Level & Name of the service centre & Total number of facilities & Type of facilities \\
\hline Union (4451) & UHSC/UHFWC & 3632 & First Aid \\
Upazila (490) & UHC & 402 & Basic \\
District (64) & District hospital, MCWC & 60 (district hospitals) 70 (MCWC) & Basic and Comprehensive \\
Division (7) & Medical college and hospital & 14 & Comprehensive \\
\hline
\end{tabular}

Source: Mridha et al (2009: 129)

Table 2. Distribution of health centres where respondents went for maternal healthcare services.

\begin{tabular}{|c|c|c|c|c|c|c|c|c|c|}
\hline \multirow{2}{*}{ Areas } & \multicolumn{9}{|c|}{ Types of health centres } \\
\hline & SM & RC & $\mathbf{U C}$ & BC & LP & NHC & SUHC & Others & TOTAL \\
\hline Bogra & 27 & 3 & 24 & 0 & 0 & 0 & 0 & 4 & 58 \\
\hline Rajshahi & 5 & 4 & 41 & 5 & 0 & 0 & 0 & 2 & 57 \\
\hline Shapahar & 0 & 0 & 0 & 0 & 2 & 14 & 8 & 0 & 24 \\
\hline Total & 32 & 7 & 65 & 5 & 2 & 14 & 8 & 6 & 139 \\
\hline
\end{tabular}

Source: Field Survey

$\mathrm{SM}=$ Shishu Mongol, $\mathrm{RC}=$ Ranirhat Clinic, UC=Urban Centre, $\mathrm{BC}=\mathrm{BRAC}$ Centre, LP=Local pharmacy, NHC=Nimtoli health centre, $\mathrm{SUHC}=$ Shapahar Upazila Health Complex.

(Note: The missing value 21 indicates that they did not receive any type of MHC services from any centre during their pregnancy. SM, UC and BC are NGO-run centres, whilst RC is private and NHC and SUHC are public)

Table 3. Distribution of nearest health centres in the study areas.

\begin{tabular}{lllll}
\hline \multirow{2}{*}{ Name of centres } & Name of areas & & & Shapahar \\
\cline { 2 - 5 } & Bogra & Rajshahi & 33 & 35 \\
\hline Union Health Sub-Centre (UHSC) & 1 & 1 & 0 & 110 \\
Urban Centre* & 53 & 0 & 0 & 4 \\
NGO run centre & 4 & 58 & 33 & 149 \\
Total & 58 & 57 & 0 \\
\hline
\end{tabular}

Source: Field Survey *This centre is under the Urban Primary Health Care Project (UPHCP)

Table 4. Distribution of healthcare facilities available at centres of areas studied where respondents visited during their conception and after delivery.

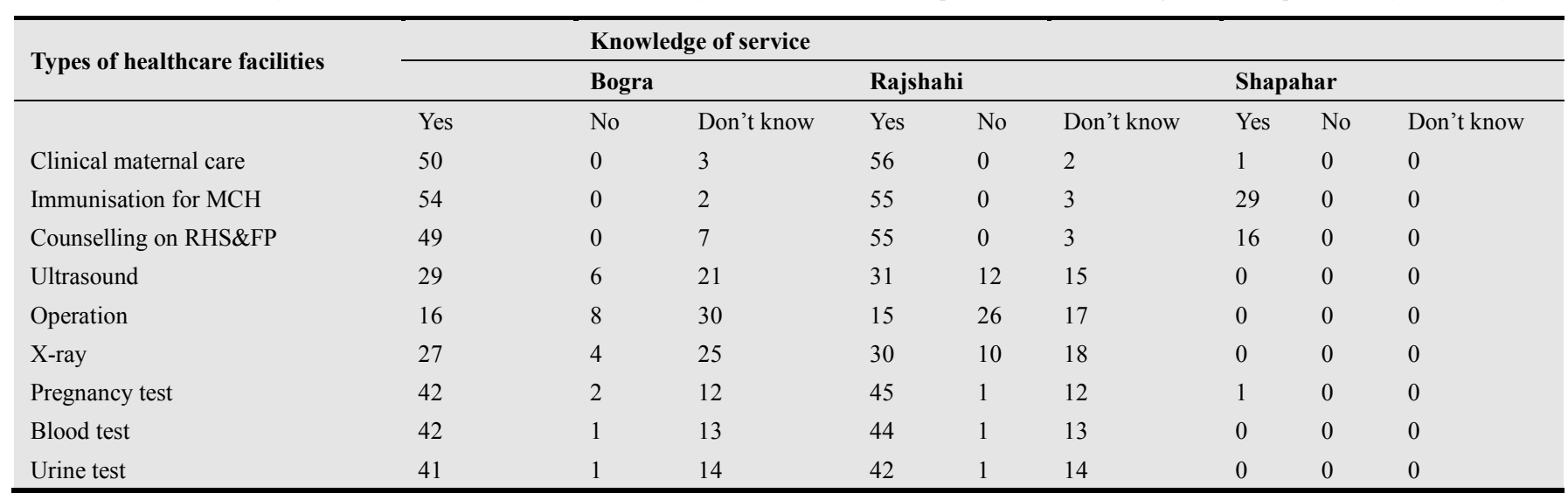

Source: Field Survey

4 Maternal and Child Welfare Centre. 


\subsection{Availability of Health Infrastructure}

Technology and technicians are not always available in rural areas. In general, there is no facility for blood-grouping and cross-matching. In some areas, even facilities for blood transfusion are absent (Anwar et al 2009: 149). The recent estimate suggests that one blood bank is available for every 523,000 people which is poor compared to the WHO's recommendation of one bank for every 100,000 to 120,000 people (McPake \& koblinsky, 2009: 103). The chief medical officer of the SUHC said during the field visit that at least one anaesthetist and a surgeon are essential for safe delivery of babies. In this regard, Huque et al (1999: 55) reported that a medical officer with no special training in obstetrics/gynaecology usually holds this position. No trained anaesthetist is posted at the UHC unless any particular project requires their presence. Even where technical facilities, such as X-ray and blood transfusion machines, were available, pregnant mothers were deprived from their use due to the lack of technicians handling them. Even if technologies are available in rural areas, lack of infrastructure and frequent breakdowns hindered their proper functioning. No electricity and water supply facilities were available at some UHSCs and UHFWCs investigated during the research and these were also unable to provide medicine according to patients' requirements. For instance, as observed, the SUHC faced black out problems most of the time and lacked an adequate supply of pharmaceutical products.

In contrast, in urban areas, many organisations, such as government, NGOs, private, and voluntary organisations, provide a range of healthcare services. Thus, town people have wider options than their rural counterparts. All organisations are expected to offer healthcare services in an efficient manner for attracting clients and may need to compete with each other for continuing their activities and services. Utility facilities (electricity, gas and water) are relatively better in towns and cities and can help in providing comprehensive healthcare services easily in emergency situations. They can also refer complicated cases to the nearest big hospitals located in major cities. For instance, the clinic manager at the Bogra Comprehensive Reproductive Healthcare Centre (BCRHCC) mentioned all available facilities, such as anaesthetics, sinology and surgery, in the centre he runs. The doctors there had training on sinology and child delivery and the staff were aware of five dangerous signs of pregnancy and three delays related to the delivery process. If they failed to treat complicated patients, they can be referred to a bigger teaching hospital located in Bogra city. Being former students of this teaching hospital and all doctors known to them, their referred patients automatically received immediate treatment on a priority basis.

Table 4 shows types of medical technologies related to healthcare that were available in the areas studied. About three-fourths of respondents in Bogra and Rajshahi knew that clinical maternal care, immunisation for mother and child, counselling on reproductive health service (RHS) and family planning (FP), pregnancy, blood, and urine tests were available in the nearest healthcare centres.

Respondents in Shapahar knew about the availability of immunisation facility for mother and child (29 of 40) and counselling on RHS and FP (16 out of 40) at their closest centres where they made visits before. Besides these six facilities, surgery, ultrasound and X-ray were less available in both Bogra and Rajshahi. Other facilities, except immunisation and counselling on RHS, were unavailable in Shapahar. It reflects the fact that rural women are more vulnerable than urban females. Nonetheless, pregnant mothers in Shapahar are used to receiving services from the government healthcare centre, whilst those in Bogra and Rajshahi have been receiving healthcare services from different organisations, particularly NGOs. Facilities of the former appear to have remained antiquarian, whereas the latter provide healthcare services incorporating all facilities relating to safe motherhood. Pregnant mothers receiving healthcare facilities from government hospitals are likely to face more complications during delivery than from the NGO-run centres.

There is a huge difference in health infrastructure between urban and rural areas. One study found that the lack of pure drinking water is one major problem for both service providers and users, whilst toilet maintenance is another issue at UHFWCs. Toilets in some centres are sometimes used as storerooms (Rahman, 2007: 8). A large number of doors and windows in 48 rural health centres are in a pitiable condition (IDRF, 2007: 21). A study, reporting on 33 rural health centres, observed that there was no standard reception room for patients and their companions in most of the centres. Even, in some cases, poor ventilation facilities were found in waiting rooms. Almost all centres were unhealthy and unhygienic. Patient privacy was hardly maintained there. In most centres, many essential equipment except blood pressure machines and stethoscopes and drugs were lacking (GUS, 2008: 27-28).

As observed during field visits, the UHFWC, situated in a rural setting, is a two storeyed building. Each floor has three rooms on the first floor and these are used as residences for the health staff. Three other rooms on the ground floor are used for rendering services. One room, consisting of six beds, is used for the admission of patients; another is used for storing medicine; and the other as a lounge for the staff. There is no waiting room for patients. They usually wait in a vacant bedroom. There is no electricity and water supply and no toilet facility for patients. The building condition is poor, discourages people from going there for services and thus needs immediate repairs. Diagnostic equipment is either missing or not in working order and the absence of ambulatory service makes it difficult to send complicated cases to upper level hospitals.

One of the possible reasons for this dismal condition is that most health-related policies fail to address the needs of local, rural people due to the fact that the policy makers are from urban areas and there is a lack of common people's participation in policy formulation. The other reason is that the government has not given due attention to the improvement of 
the rural health infrastructure. For instance, the budget (201213) did not allocate any extra or special money for rural health infrastructure development (Daily Star, June 8, 2012).

The government hospitals in urban areas are neither hygienic nor user friendly. Most of the district hospitals have been upgraded without ensuring a sufficient supply of necessary items, such as equipment, beds, pharmaceuticals and skilled health personnel. Patients were found to be lying on the floor. Imaging equipment have been out of order for long periods (Akter et al 2008; Bilu, 2010; Daily Star, Februray 13, 2011; Daily Star, October 13, 2011). In one study, for instance, a medical officer summed up the real situation of an orthopaedic ward in a big national hospital situated in Chittagong, the second largest city: "Today there are 118 patients in the ward. We have only 92 beds. You can see that the rest are lying on the floor (Zaman, 2004: 2030)." Anecdotal evidence suggests that policy experts have good access to private healthcare facilities. So they hardly give attention to the physical conditions of government hospitals.

By comparison, as observed by the researcher, NGO-run urban centres are in far better condition. For instance, each urban centre is housed in a two-storeyed building. The facade is very attractive making patients cheerful and comfortable in seeking healthcare services there. There are rooms for the clinic manager/medical officer, paramedics, counsellor and service promoters on the first floor. Besides these, a room with fan, television and bathroom has been dedicated for waiting patients, while another is used for storing medicines and other items. The clinic is equipped with diagnostic apparatuses to test the general condition of patients immediately. The operation room is air-conditioned. The centre can easily dispatch complicated cases to tertiary level hospitals with its ambulatory service.

\subsection{Availability of Health Personnel}

Bangladesh has a huge shortage of qualified health care providers (QHCPs) compared with other South Asian countries (Ahmed et al 2011) despite increasing the numbers of QHCPs by 38,805 between 1999 and 2010 (MOHFW, 2010) and recruiting around 39,000 recently in the last couple of years (bdnews24, Februray 7, 2012). The density of the QHCPs per 10,000 in Bangladesh is 7.7, way less than the international standard (23) set by WHO in 2006, whereas that in Sri Lanka, India and Pakistan is 21.9, 14.6 and 12.5 respectively (Ahmed et al 2011). As of 2007, the total numbers of doctors, nurses and health technologists ${ }^{5}$ were $38,537,15,023$, and 9,230 respectively although, according to the WHO standard for meeting health-related MDGs, Bangladesh needs 98,550 doctors, 295,450 nurses, and 492,750 health technologists. Thus, there is an acute shortage of health professionals in the country.

The current estimate suggests that among health care

5 They include sanitary inspectors, dentists, laboratory technicians, pharmacists, radiographers and physical therapists. providers (HCPs), 5.2 percent are skilled $^{6}$ and 1.3 percent semi-skilled ${ }^{7}$ (BHW, 2007). Among unqualified health care providers [UHCPs] $-93.5 \%$ serving 80 percent of population, the most available HCPs are traditional healers ${ }^{8}(43 \%)$, followed by traditional birth attendants (22\%), village doctors (9\%), sellers of allopathic medicine (8\%), community health workers [CHWs] (7\%), and homeopaths (4\%) (BHW, 2007; El-saharty \& Ahsan, 2011). A study revealed that 16 percent of rural pregnant women with complications received treatment from QHCPs. The rest went to either village doctors or homeopaths or, in some cases, none of these. Another study found most rural pregnant mothers were making contacts with UHCPs before visiting UHCs. One in five of them went to traditional practitioners, such as untrained village allopath and homeopaths (Khanum et al 2000). Another study, suggests that inadequacy of competent health personnel jeopardises sexual and reproductive health (SRH) services in the safe motherhood project area. It indicates that altogether 62 facility centres with only 109 doctors, 126 paramedics and 205 nurses were available for providing SRH services to 1.8 million people (Barkat et al 2006).

The main reasons for the high acceptability of UHCPs services, particularly in rural areas, are deeply embedded in the local community: respect for local customs and rituals, no extra fees charged for consultancy, easiness of approach whenever help is needed, and the availability of better options to pay for medicine costs, such as deferring payments, paying in kind instead of cash, etc (Ahmed \& Hossain, 2007; Ahmed et al 2009; Begum, 1997; BHW, 2007; khanum et al 2000; Wahed et al 2010).

Healthcare, particularly maternal, services are imperilled due to the shortage of skilled manpower. For instance, the dearth of obstetricians and anaesthetists has been there since independence. As of 2006, there were 873 specialists in gynaecology and obstetrics (Mridha et al 2009) though another data set claimed the number to be 1,070 (Minca, 2011). If 15 percent of pregnant mothers with complications sought specialist care, each gynaecologist and obstetrician would need to treat around 514 childbirth-related cases each year. As they are involved in different activities other than providing comprehensive MHC services, the actual number could be less than the hypothesised number. In order to address the shortage of skilled manpower in the health sector, the government took the step of providing one-year training for medical graduates (MBBS) in each specialist area. According to the 2007 data set, 156 graduates received training on obstetrics (Mridha et al 2009: 136). In 2003, the government also took another bold step by creating a community-based skilled birth attendants (CSBAs) cadre with technical and financial assistance from the WHO and

6 Physicians (3.7\%), nurses (1.3\%) and dentists $(0.2 \%)$.

7 It includes Medical Assistants/Sub Assistant Community Medical Officers,

Family Welfare Visitors, and lab technicians or physiotherapists.

8 Kaviraj, totka, herbalist and faith healers are included here. 
the UNFPA. With the help of the Obstetrical and Gynaecological Society of Bangladesh (OGSB), it has initiated six months long training to two groups of lower level health workers (LLHWs) - Family Welfare Assistants (FWAs) and female Health Assistants working at ward level. Along with the OGSB, the Family Welfare Visitor Training Institute, nursing institutes and MCWCs also provide this training to these local two groups of health workers. On average, 480 CSBAs are produced annually. As of 2007, 3,000 CSBAs were trained from 216 upazilas (BHW, 2007). Though the number of specialised personnel has been increasing gradually, the government fails to develop enough skilled manpower, deploy and retain them in rural areas (Mridha et al 2009).

However, the number of health personnel in both public and private sectors has been increasing. The number of registered physicians, nurses and midwives increased from $29,746,16,972$ and 14,915 to $51,993,25,018$ and 23,472 in that order between 1999 and 2010. This indicates that the number of physicians has been increasing more quickly than nurses and midwives (primary caregivers to expectant mothers) in the last decade. It also indicates that the ratio of population per physician and nurse has been decreasing; population per physician and nurse in 1999 was 4,521 and 7,923 correspondingly, whilst, in 2010 , it is 2,785 and 5,782 respectively. However, despite the increasing number of physicians and nurses, the ratio of physician-nurse is increasing; it was 2:1 in 1999, while it is $2.07: 1$ in 2010 (MOHFW, 2000; MOHFW, 2010). It hints that the nursephysician gap is widening which is unusual in other countries and quite far from the standard distribution of three nurses per one physician (BHW, 2007). For instance, equal numbers of nurses and physicians are available in South Central Asia and Latin America, whereas there are three or more nurses per physician in Africa, North America and Europe (Leslie \& Gupta, 1989: 9-10). As of 2001, the physician-nurse ratio in India, Nepal, Pakistan and Sri Lanka was 0.83, 0.19, 1.4 and 0.54 respectively (Hongoro \& McPake, 2004: 1452). It has been suggested that the ratio in Bangladesh is better than Pakistan and worse compared with the other three South Asian countries.

The persistent gap between physician and nurse in Bangladesh has been attributed to the prevailing socioeconomic situation, including the cultural preference condition. There is a misconception and social stigma about the nursing profession in the country. This profession is perceived as a female-oriented low level and 'unclean' job as it usually does not require intelligence and income associated with this profession is very low compared to others (NursingPromotion-in-Bangladesh, n.d). This wrong perception dissuades both Muslim and Hindu parents from sending their daughters to take up this profession unless situation compels them (Anwar et al 2009: 152; Darr et al 2008: 157; Zaman, 2009: 367). In addition, sometimes people associate the nursing profession with 'prostitution' and see it as an 'immoral' profession as they stay in the hospitals or nursing centres at night with doctors (lady doctors are normally off duty at night) and other males. For this reason, their demand in the marriage market is low. Even if doctors marry nurses, they are teased for marrying them (Hadley et al 2007: 1170; Zaman, 2009: 371).

Women from middle and higher classes are therefore not willing to engage in this profession as career advancement to higher levels in this profession is not guaranteed. Generally, females of poorer families, widows and destitute women reluctantly accept a career in nursing, since finding work as a nurse is comparatively easier than other professions (Hadley et al 2007; Madden et al 2011; Zaman, 2009). Through training and practice, they become skilled workers who prefer migrating to developed countries for earning more money that could help mitigate the financial crises of their families. This overseas migration of skilled nurses is another important reason for widening the ratio gap. For instance, in 1991-2004, more than five percent of female labour migrants abroad were reported to be nurses (Aminuzamman, 2007: 14). As of 2007, 40 percent of nurses in Malaysia were from different nationalities, including Bangladesh (Matsuno, 2009: 14).

Healthcare services in the public sector are affected due to failure in filling vacant posts, though the number of health staff, it has been claimed, is increasing. For instance, the current estimate hints that around 20 percent of sanctioned posts are vacant. Most vacancies are in nursing at upazila level (El-saharty \& Ahsan, 2011). According to another dataset, at government level, in comparison to the health sector, more sanctioned posts in FP and nursing sectors were found to be vacant. More shortages in the class II category in both health and FP sectors and class I in the nursing sector have been reported. In 2011, the percentages of vacant posts for class 1 staff in health, FP and nursing were 24.33, 48.21, and 98.80 respectively. The figures for vacancy in class II staff were $30.79 \%$ (health), 59\% (FP) and 70.72\% (nursing) (MOHFW, 2011). There are more vacancies at lower levels than at higher. As of March 2007, 500 medical officers (Maternal child health-family planning), 66 medical officers (family welfare), 2,089 sub-assistant community medical officers, and 5,075 FWVs were present against 716, 250, 2,500, and 5,705 allotted posts respectively (GUS, 2008: 1).

The field report based on observation of the SUHC indicates the same condition at grassroots level. It found seven (class-I) against 26 sanctioned posts, 45 (class-III) in place of 73, and 18 (class-IV) against 28 staff were available. The highest number of vacancies was noticed at the upper strata responsible for providing healthcare services. The question arises why the government fails to fill-up vacancies, particularly in rural areas. Migration of health staff to overseas and urban centres has complicated the recruitment process and emerging private and NGO sectors are the main causes of this situation. As said earlier, different pull factors push QHCPs to work for either NGOs or private sector organisations. For instance, Banik (2010) and BHW (2007) hint that NGOs are paying competitive salaries to all HCPs which are higher than those paid in government positions. The clinic manager of the BCRHCC told during his interview that he was in this clinic for around two years because of longer project duration, high 
salary, many facilities and the possibility of transforming the project into a revenue-earning initiative. Another medical officer, working in an NGO clinic in Rajshahi, complained against the doctors' recruitment process in the government sector. She believes that doctors should have the opportunity to enter directly into the public sector after finishing their internships and follow a separate recruitment process.

In the public sector, the recruitment procedure is more bureaucratic and time consuming. It may take more than three years to complete the process. In general, many steps need to be followed to create a new post in the Ministry of Health and Family Welfare (MOHFW) and it takes between six months and two years to complete the process ${ }^{9}$. The recruitment procedure is sometimes obstructed for political reason. Strangely, the recruitment process for LLHWs has often been halted for not inducting governing party workers (Daily Star, February 1, 2010; Zannat, 2011).

\subsection{Accessibility to Primary Healthcare Services}

Physical infrastructures or availability of healthcare services does not mean that people have easy access to them. Yet, people's accessibility to PHC, including maternal, services has been steadily improving since the 1990s. For instance, the percentages of mothers in receipt of at least one ANC service increased by four between three years. The figure for 2004 was 56 percent, whilst it was 60 in 2007. Moreover, between 2004 and 2007, the coverage rate of qualified doctors in ANC services increased from 31.3 to 35.5 percent, whereas that of nurse/midwife/paramedic went down to 15.7 from 17.4 percent (NIPORT et al 2005; NIPORT et al. 2009). Anyway, this increase has been caused by inbuilt program components of the Health and Population Sector Program (HPSP, 1998-2003) and Health, Nutrition and Population Sector Program (HNPSP, 2003-10), the presence of one-stop service delivery centres, women's education, empowerment and behavioural change communication (BCC) programs (Hossain, 2010: 404). By contrast, for two or more tetanus toxoid injections, one vital component of the ANC service, the up-taking rate dropped from 63.6 to 59.7 percent between 2004 and 2007. The shortage of tetanus injections at government level and the perceived idea about no further need to inject pregnant mothers who had it before could be the result of this low rate (NIPORT et al 2009: 109).

Mothers' accessibility to facility centres for delivering their babies also improved. In 2004, six and three percent of mothers delivered babies in public and private health facilities respectively, whereas it was turned into seven and around eight percent correspondingly in 2007. That means,

9 The first step is that the MOHFW proposes the Ministry of Establishment for creating a new post by identifying the necessity for it. The Ministry of Finance then creates funding for this new post, approved by the Establishment Ministry. The proposal is finally tabled for the cabinet approval. Once the proposal is finally approved in the cabinet meeting, the National Implementation Committee for Administrative Reforms permits the MOHFW to advertise the sanctioned post. It may take a further three months or more to fill up the post (El-saharty \& Ahsan, 2011). mothers' preference for home delivery went down. In addition, the percentage of mothers receiving assistance from qualified doctors at delivery rose to 12.7 (2007) from 7.5 (2004) (NIPORT et al 2005; NIPORT et al 2009). It also documented that mothers' accessibility to MHC facilities increased slightly between 2000 and 2003. The percentage of babies delivered at government facilities, private or NGO-run clinics, and home was seven, four, and 89 respectively, while it was six each at government and private and 84 at home in 2003 (Cockcroft et al 2004: 5). The respondents of the study (Table 5) stated that they went to the nearest centres for MHC services. Around 84 percent of mothers visited their nearest centres from one to four times. That indicates, most pregnant mothers went there for essential check-up and medicine, important for both mother and child.

Table 5. No. of times respondents visited the nearest centres for maternal health care.

\begin{tabular}{llll}
\hline Range of visit times & Frequency & Percent & Cumulative Percent \\
\hline $1-4$ & 118 & 84.3 & 84.3 \\
$5-8$ & 15 & 10.7 & 95.0 \\
$9-12$ & 6 & 4.3 & 99.3 \\
$12-16$ & 1 & .7 & 100.0 \\
Total & 140 & 100.0 & \\
\hline
\end{tabular}

Source: Field Survey

\section{Conclusion}

The availability of PHC facilities in both public and private sectors is increasing although the EmOC facility is yet to reach international standards. Four in five mothers went for MHC services at least once at their nearest centres. However, all these facilities are not evenly distributed. All healthcare-related facilities, such as blood transfusion, ultra sonogram, and Caesarean, are more available in urban than rural areas. However, the shortage of health personnel, particularly specialised in maternal health, the unusual ratio of physician and nurse, the uneven distribution of QHCPs and health infrastructure and lack of recognition of UHCP contribution to healthcare services in the mainstream health system all jeopardise MHC services.

Public healthcare centres in both urban and rural areas are not user-friendly due to lack of policy makers' attention and lack of sufficient allotment in budget, whereas the NGO-run centres, mostly located in urban areas, are better equipped. Healthcare infrastructure (building condition, facilities for waiting patients) is more attractive in urban and the private, including NGO, sector than in rural and the public sector. Many facilities for immediate diagnosis of patients are conveniently available in urban areas compared to the rural. The QHCPs (6.5\%) serve only 20 percent of the population and they want to remain in urban areas. If the public sector urban facilities fail to treat, they usually switch to the NGOrun centres, which are mostly urban-based. The UHCPs (93\%) give services to 80 percent of people.

The majority of urban mothers had access to NGO-run healthcare centres, whereas six in ten rural mothers had 
access to the government services. The rest (4 in 10) rural mothers received no MHC services from any centre. A large number of urban mothers received clinical maternal care, immunisation for themselves and their children, counselling on RHS and FP. Around three-quarters could obtain pregnancy, blood and urine test facilities. Less than half had facilities for ultrasound, operation and X-ray. By contrast, three-fourth and less than half of rural mothers received immunisation for themselves and their children, and counselling on RHS and FP respectively.

The shortage and absence of health personnel are acute in rural areas. Urban mothers received healthcare services from both doctors and $\mathrm{CHWs}$, while rural mothers receive the same services from only CHWs. Six in 10 mothers delivered babies at home. However, the tendency of urban mothers to deliver babies at facility centres is more compared to rural mothers. That means, urban mothers had total access to Caesarean section.

Lack of recognition of nursing as a profession is the cause of higher physician-nurse ratio. Nursing has for long been considered a female-oriented low level profession and sometimes associated with prostitution. For this reason, parents of middle and higher classes do not encourage their daughters to choose this profession. Overseas migration and religious ideology appear to work as reasons for this situation Job opportunities in government are higher than in the nongovernment sector. Higher salary structure, easy recruitment process and other facilities encourage HCPs of the NGO sector to stay there. By contrast, complex recruitment procedures and political intervention create obstacles to filling up vacant posts in the government sector. All these shortcomings (low physician-nurse ratio, vacancy, highly bureaucratic and time consuming recruitment process) in the public sector create obstacles to catering to the needs of primary, particularly maternal, healthcare services in rural and poor areas which are easily available in the private and NGO sectors of the urban areas.

\section{Appendix}

Table 1. Demographic profile of the respondents.

\begin{tabular}{llll}
\hline Different categories & Frequency & Percent & Cumulative percent \\
\hline Age & & & \\
$15-20$ & 33 & 20.6 & 20.6 \\
$21-25$ & 65 & 40.6 & 61.2 \\
$26-30$ & 36 & 22.5 & 83.7 \\
$31-35$ & 17 & 10.6 & 94.3 \\
$36+$ & 9 & 5.7 & 100 \\
Total & 160 & 100 & \\
Marital Status & & & \\
Married & 155 & 96.8 & \\
Widowed & 3 & 1.9 & \\
Divorced & 2 & 1.3 & \\
Total & 160 & 100 & \\
Age at marriage & & & \\
$11-15$ & 47 & 29.4 & 29.4 \\
$16-20$ & 96 & 60.0 & 89.4 \\
$21-25$ & 11 & 6.8 & 96.2 \\
$26+$ & 6 & 3.8 & 100 \\
\hline
\end{tabular}

\begin{tabular}{llll}
\hline Different categories & Frequency & Percent & Cumulative percent \\
\hline Total & 160 & 100 & \\
Educational & & & \\
qualification & & & \\
Illiterate & 63 & 39.3 & 39.3 \\
Primary & 44 & 27.5 & 66.8 \\
Secondary & 50 & 31.2 & 98.0 \\
Higher-secondary & 3 & 2.0 & 100 \\
Total & 160 & 100 & \\
No. of family & & & \\
members & & & \\
1-3 & 125 & 78.1 & 78.1 \\
4-6 & 30 & 18.7 & 69.8 \\
$7-9$ & 5 & 3.2 & 100 \\
Total & 160 & 100 & \\
\hline
\end{tabular}

Source: Field Survey

Table 2. Socio-economic characteristics of the respondents.

\begin{tabular}{|c|c|c|}
\hline Different characteristics & Frequency & Percent \\
\hline \multicolumn{3}{|l|}{ Religion } \\
\hline Islam & 99 & 62 \\
\hline Hindu & 54 & 34 \\
\hline Christian & 3 & 2 \\
\hline Adhivasi $^{10}$ & 3 & 2 \\
\hline Total & 159 & 100 \\
\hline \multicolumn{3}{|c|}{ Occupation (Multiple answers) } \\
\hline Housewife & 152 & 91.6 \\
\hline Job & 1 & 0.6 \\
\hline Housemaid & 5 & 3.0 \\
\hline Agriculture & 8 & 4.8 \\
\hline Total & 166 & 100 \\
\hline \multicolumn{3}{|c|}{ Income level (family monthly) } \\
\hline Below 5000 & 69 & 43.9 \\
\hline $5001-10,000$ & 79 & 50.3 \\
\hline Above 10,000 & 9 & 5.8 \\
\hline Total & 157 & 100 \\
\hline \multicolumn{3}{|l|}{ Household patterns } \\
\hline Kutcha $^{11}$ & 114 & 71.2 \\
\hline Pucca $^{12}$ & 8 & 5.0 \\
\hline Semi-pucca ${ }^{13}$ & 29 & 18.1 \\
\hline Tin & 9 & 5.7 \\
\hline Total & 160 & 100 \\
\hline \multicolumn{3}{|c|}{ Household furniture (multiple answers) } \\
\hline Bed & 129 & 81 \\
\hline Box & 120 & 75 \\
\hline Clothes hanger $^{14}$ & 108 & 68 \\
\hline Table & 8 & 5 \\
\hline Neither & 28 & 18 \\
\hline \multicolumn{3}{|c|}{ Consumer items (multiple answers) } \\
\hline Television & 64 & 40 \\
\hline Refrigerator & 12 & 8 \\
\hline Mobile & 11 & 7 \\
\hline Fan & 35 & 22 \\
\hline Radio & 3 & 2 \\
\hline VCD & 9 & 6 \\
\hline Cycle & 6 & 4 \\
\hline Neither & 59 & 37 \\
\hline
\end{tabular}

Source: Field Survey

10 Aboriginal religion

11 The walls and/or roofs of houses are made from materials such as un-burnt bricks, bamboos, mud, grass, tin, etc.

12 The walls of house are made with burnt bricks and roof is concrete.

13 The walls of burnt bricks and roof are made of corrugated tin.

14 Keeping clothes and valuable items 


\section{References}

[1] Ahmad, A (2003) Provision of Primary Health Care in Bangladesh: An Institutional Analysis; Lund, Sweden: Lund University, Department of Economics, Working Papers, No. 2003:18 (August).

[2] Ahmed, S. M., Adams, A. M., Chowdhury, M., \& Bhuiya, A (2000). Gender, socioeconomic development and health seeking behaviour in Bangladesh. Social Science \& Medicine, 15, 361-371.

[3] Ahmed, S M (2002) Healthcare provision from static centres and the issue of self-financing: Experiences of selected NGOs; Dhaka, Bangladesh: BRAC Research Report on Health (February).

[4] Ahmed, S. M., Adams, A. M., Chowdhury, M., \& Bhuiya, A. (2003). Changing health-seeking behaviour in Matlab, Bangladesh: do development interventions matter? Health Policy and Planning, 18(3), 306-315.

[5] Ahmed, S. M., \& Hossain, A. (2007). knowledge and practice of unqualified and semi-qualified allopathic providers in rural Bangladesh: Implications for the HRH problem. Health Policy, 84, 332-343.

[6] Ahmed, S. M., Hossain, A., \& Chowdhury, M. R. (2009). Informal sector providers in Bangladesh: how equipped are they to provide rational health care? Health Policy and Planning, 24, 467-478.

[7] Ahmed, S. M., Hossain, A., Chowdhury, A. M. R., \& Bhuiya, A. U. (2011). The health workforce crisis in Bangladesh: shortage, inappropriate skill-mix and inequitable distribution. Human Resources for Health, 9(3), 1-7.

[8] Ahmed, S. M \& Islam, Q. S. (2012). Availability and Rational Use of Drugs in Primary Healthcare Facilities Following the National Drug Policy of 1982: Is Bangladesh on Right Track? Journal of Health, Population, and Nutrition, 30(1), 99-108

[9] Akter, S., Upal, M., \& Hani, U. (2008). Service quality perception and satisfaction: A study over sub-urban public hospitals in Bangladesh. Journal of Service Research, Special Issue, 125-146.

[10] Alkire, S., \& Santos, M. E. (2010). Multidimesional Poverty Index. OPHI Research Brief.

[11] Aminuzamman, S. M. (2007). Migration of skilled nurses from Bangladesh: an exploratory study. Brighton, UK: University of Sussex Development Research Center on Migration, Globalization and Poverty.

[12] Anwar, I., Kalim, N., \& Koblinsky, M. (2009). Quality of obstetric care in public-sector facilities and constraints to implementing emergency obstetric care services: evidence from high-and low-performing districts of Bangladesh. Journal of Health, Population, and Nutrition, 27(2), 139-155.

[13] Banik, B. K. (2003). Effectiveness of Health System: A Comparison between Bangladesh and Sri Lanka Social Science Journal, 8, 251-266.

[14] Banik, B. (2010). Inclusion or Exclusion of the Urban Poor?: The case of the UPHCP, Rajshahi, Bangladesh. Saarbrucken, Germany: Lambert Academic Publishing.
[15] Barkat, A., Rahman, M., Bose, M. L., \& Akhter, S. (1997). Modelling the first two delays of the "three-delays model" for emergency obstetric care in Bangladesh: a choice model approach. J Health Popul Dev Count, 1(1), 57-67.

[16] Barkat, A., Ara, R., Majid, M., Mohiyuddin, G., Uddin, T., Sabina, N., . . . Hoque, S. (2006). Baseline Study on Increasing Access to Maternal Health Services for Poor Women in Rural Bangladesh. Dhaka: Human Development Research Centre (HDRC).

[17] bdnews24. (February 7, 2012). Recruiting 39000 physiciannurse in three years, bdnews24.com.

[18] Begum, S. (1997). Health Dimension of Poverty in Rural Bangladesh: Some Evidence. Dhaka: Bangladesh Institute of Development Studies.

[19] BHW. (2007). The State of Health in Bangladesh 2007 Health Workforce in Bangladesh: Who Constitutes the Healthcare system? Dhaka: Bangladesh Health Watch (BHW), BRAC Univesity.

[20] BIDS. (2003). Micro Impacts of Macroeconomic and Adjustment Policies in Bangladesh(MIMAP) Technical Paper no 8 Retrieved 5th November, 2009, from www.mdgbangla.org/mdg_issues/.../poverty_data_bids.htm

[21] Bilu, H. R. (2010). Naogaon hospital upgraded, services downgraded, The Daily Star, March 16.

[22] Cockcroft, A., Milne, D., \& Anderson, N. (2004). Bangladesh Health and Population Sector Program 1998-2003: A Summary of the final Report of the third Service Delivery Survey 2003. Dhaka: Ministry of Health and Family Planning, People's Republic of Bangladesh, The CIET, Canada.

[23] Coppe, P., Pisani, L. and Keita, A. (1992). Perceived Morbidity and Health Behaviour in a Dogon Community. Social Science \& Medicine, 34 (11), 1227-1235

[24] Daily-Star. (February 1, 2010). Jubo League men go on rampage over recruitment, The Daily Star.

[25] Daily-Star. (February 13, 2011). For better managed hospitals, The Daily Star.

[26] Daily-Star. (October 13, 2011). Jamalpur hospital runs without ultra-sonogram machines, The Daily Star. Daily-Star. (March 1, 2012). Safe motherhood left in the lurch, The Daily Star.

[27] Daily-Star. (June 8, 2012). Healthcare in remote areas not addressed, The Daily Star.

[28] Darr, A., Atkin, K., Johnson, M., \& Archibong, U. (2008). The recruitment of South Asian people into the nursing profession: A knowledge review. Journal of Research in Nursing, 13(2), 151.

[29] Desmet, M., Bashir, I., Rahman, H., Sayeeduzzaman, M., and Chowdhury, Q. (1999). Can We Provide a more Appropriate Health Care in Bangladesh. In N. Islam (Ed). Sociology Health Women and Environment (pp. 99-100). Dhaka. Bangladesh Sociological Association

[30] Dewan, F. (n.d). Meeting the Need for Emergency Obstetric Care in Bangladesh, from http://www.esdproj.org/site/DocServer/MAT6 Farhana Dewa n.pdf?docID $=1033$ 
[31] El-saharty, S., \& Ahsan, K. Z. (2011). Bangladesh Human Resources for health: Bridging the gap. Paper presented at the Health Systems Reform in Asia, Hongkong.

[32] Germov, J. (2002). Imagining Health problems as Social Issues. In J. Germov (Ed.), Second Opinion: An Introduction to Health Sociology (2nd ed., pp. 3-27). Victoria: Oxford University Press.

[33] GoB. (1998) The Fifth Five-Year Plan 1997-2002. Dhaka. The Planning Commission, the Government of Bangladesh (GoB).

[34] GUS. (2008). Effect of Vacancies in MC-RH Service Delivery System. Dhaka: Gano Unnayan Sangstha (GUS).

[35] Hadley, M. B., Blum, L. S., Mujaddid, S., Parveen, S., Nuremowla, S., Haque, M. E., \& Ullah, M. (2007). Why Bangladeshi nurses avoid "nursing": Social and structural factors on hospital wards in Bangladesh. Social Science \& Medicine, 64(6), 1166-1177.

[36] Hongoro, C., \& McPake, B. (2004). How to bridge the gap in human resources for health. Lancet, 364, 1451-1456.

[37] Hossain, S., Alec, M., Jahanara, K., Yousuf, H., Jasim, U., Humayun, K., Nowsher, U., and Nirod, C. S (2003) Operations research on ESP delivery -- Addressing missed opportunities for service provisions in primary healthcare clinics; Dhaka, Bangladesh: International Centre for Diarrhoeal Disease Research, Bangladesh (ICCDR,B), Working Paper, No. 159.

[38] Hossain, A., D. H. Luong., Shahaduz, Z and Tran, T M O (2005) Primary Healthcare in Later Life--Improving Services in Bangladesh and Vietnam (PHILL): Post-intervention Report on Qualitative Data; Dhaka, Bangladesh: BRAC Research Report on Health (November).

[39] Hossain, J., \& Ross, S. R. (2006). The effect of addressing demand for as well as supply of emergency obstetric care in Dinajpur, Bangladesh. International Journal of Gynecology \& Obstetrics, 92, 320-328.

[40] Hossain, A. H. M. K. (2010). Utilization of Antenatal Care Services in Bangladesh: An Analysis of Levels, Patterns, and Trends From 1993 to 2007. Asia Pacific Journal of Public Health, 22(4), 395-406.

[41] Huque, Z. A., Leppard, M., Mavalankar, D., Akhter, H. H., \& Chowdhury, T. (1999). Safe motherhood programmes in Bangladesh. In M. Berer \& T. K. S. Ravindran (Eds.), Safe Motherhood Initiatives: Critical Issues (pp. 53-61). Oxford, UK: Blackwell Science for Reproductive Health Matters.

[42] IDRF. (2007). Identify the Barriers of Keeping the FWVs/SACMOs in Their Work Situation/Station. Dhaka: Integrated Development and Research Foundation (IDRF) and National Institute of Population Research and Training (NIPORT).

[43] Islam, A., \& Tahir, M. Z. (2002). Health sector reform in South Asia: new challenges and constraints. Health Policy, 60 , 151-169.

[44] Islam, M., Hossain, M., Islam, M., \& Haque, Y. (2005). Improvement of coverage and utilization of EmOC services in southwestern Bangladesh. International Journal of Gynecology and Obstetrics, 91(3), 298-305.
[45] Khanum, P., Quaiyum, M., Islam, A., \& Shameem, A. (2000) Complications of Pregnancy and Childbirth: Knowledge and Practices of Women in Rural Bangladesh. Vol. ICDDR,B Working Paper No.131. Dhaka: ICDDRB.

[46] Kleinmann, A. (1980). Patients and Healers in the Context of Culture. Berkley. University of California Press

[47] Koehlmoos, T. P., Islam, Z., Anwar, S., Hossain, S. A. S., Gazi, R., Streatfield, P. K., \& Bhuiya, A. U. (2011). Health Transcends Poverty: The Bangladesh Experience. In D. Balabanova, M. McKee \& A. Mills (Eds.), 'Good health at low cost' 25 years on. What makes a successful health system? (pp. 47-81). London: London School of Hygiene \& Tropical Medicine.

[48] Leslie, J., \& Gupta, G. R. (1989). Utilization of formal services for maternal nutrition and health care in the Third World: International Center for Research on Women Washington, DC.

[49] Madden, M., Burke, C., \& McCormack, C. (2011). Bangladesh 2010-2011 Retrieved February, 23, 2012, from http://www.uvm.edu/ kappatau/2011/GlobalLeadership/_Ban gladesh.pdf

[50] Marshall, A. A., \& McKeon, J. K. (1996). Reaching the "Unreachables": Educating and Motivating Women Living in Poverty. In E. B. Ray (Ed.), Communication and Disenfranchisement: Social Health Issues and Implications (pp. 137-158). New Jersey: Lawrence Erlbaum Associates, Publishers.

[51] Matsuno, A. (2009). Nurse Migration: The Asian Perspective. ILO/EU Asian Programme on the Governance of Labour Migration Technical Note Retrieved February, 22, 2012, from www.pstalker.com/.../Technical $\% 20$ Note $\% 20-\ldots$

[52] McPake, B., \& Koblinsky, M. (2009). Improving Maternal Survival in South Asia-What Can We Learn from Case Studies? Journal of Health, Population and Nutrition, 27(2), 93-107.

[53] Minca, M. (2011). Midwifery in Bangladesh: In-depth country analysis. Background document prepared for the State of the World's Midwifery Report 2011.

[54] MOHFW. (2000). Health Bulletin 1998-99. Dhaka: Ministry of Health and Family Welfare, Government of the People's Republic of Bangladesh.

[55] MOHFW. (2010). Health Bulletin 2010. Dhaka: Management Information System (MIS), Director General of Health Services (DGHS). Ministry of Health and Family Welfare (MOHFW), Dhaka, Bangladesh

[56] MOHFW. (2011). HRD Data Sheet-2011. Dhaka: Human Resources Development Unit, Ministry of Health and Family Welfare (MOHFW), Government of the People's Republic of Bangladesh.

[57] Mridha, M. K., Anwar, I., \& Koblinsky, M. (2009). Publicsector maternal health programmes and services for rural Bangladesh. Journal of health, population, and nutrition, 27(2), 124-138.

[58] NIPORT. (2001). Bangladesh Demographic and Health Survey 1999-2000 Retrieved 5th November, 2009, from http://www.mdgbangla.org/mdg_issues/improve_maternal_hlt/ improve_maternal_hlt_data.htm 
[59] NIPORT, Associates, M. A., \& International, M. (2009). Bangladesh Demographic and Health Survey, 2007. Dhaka, Bangladesh and Calverton, Maryland, USA: National Institute of Population Research and Training (NIPORT), Mitra and Associates, and Macro International.

[60] NIPORT, Associates, M. A., \& International, M. (2005). Bangladesh Demographic and Health Survey, 2004. Dhaka, Bangladesh and Calverton, Maryland, USA: National Institute of Population Research and Training (NIPORT), Mitra and Associates, and Macro International.

[61] NIPORT, Associates, M. A., \& International, M. (2012). Bangladesh Demographic and Health Survey, 2011: Preliminay Report. Dhaka, Bangladesh and Calverton, Maryland, USA: National Institute of Population Research and Training (NIPORT), Mitra and Associates, and Macro International.

[62] Nursing-Promotion-in-Bangladesh. (n.d). Carrer PlanningNursing Pespective Retrieved 11th October, 2011, from www.npib-bd.com

[63] Osman, F. A. (2004). Policy Making in Bangladesh: A Study of the Health Policy Process. Dhaka: A.H. Development Publishing House.

[64] Osman, F. A. (2008). Health Policy, Programmes and System in Bangladesh: Achievements and Challenges. South Asian Survey, 15(2), 263-288.

[65] Osmani, S. R. (2010). Realising the Right to Development in Bangladesh: Progress and Challenges. The Bangladesh Development Studies, XXXIII(1\&2), 25-90.
[66] Pearson, M. (1999) 'Bangladesh: Health Briefing Paper', London. DFID Health System Resource Centre in $\mathrm{http}: / /$ www.healthsystemsrc.org/publications/countryhealth/Bangladesh.pdf. accessed. April, 3. 2006.

[67] Rahman, M., Ashaduzzaman, A. S. M., \& Rahman, M. (2005). Poor People's Access to Health Services in Bangladesh: Focusing on the Issues of Inequality. Paper presented at the Network of Asia-Pacific Schools and Institutes of Public Administration and Governance Annual Conference, Beijing.

[68] Rahman, A. P. M. S. (2007). Situation Analysis of Union Health and Family Welfare Center (UHFWC). Dhaka: National Institute of Population Research and Training (NIPORT)

[69] Wahed, T., Moran, A. C., \& Iqbal, M. (2010). The perspectives of clients and unqualified allopathic practitioners on the management of delivery care in urban slums, Dhaka, Bangladesh-a mixed method study. BMC Pregnancy and Childbirth, 10(1), 50.

[70] Zaman, S. (2004). Poverty and violence, frustration and inventiveness: hospital ward life in Bangladesh. Social Science \& Medicine, 59(10), 2025-2036.

[71] Zaman, S. (2009). Ladies Without Lamps: Nurses in Bangladesh. Qualitative Health Research, 19(3), 366-374.

[72] Zannat, M. (2011). Graft halts technician recruitment, The Daily Star, September 15. 